\title{
A novel transcript of MEF2D promotes myoblast differentiation and its variations associated with growth traits in chicken
}

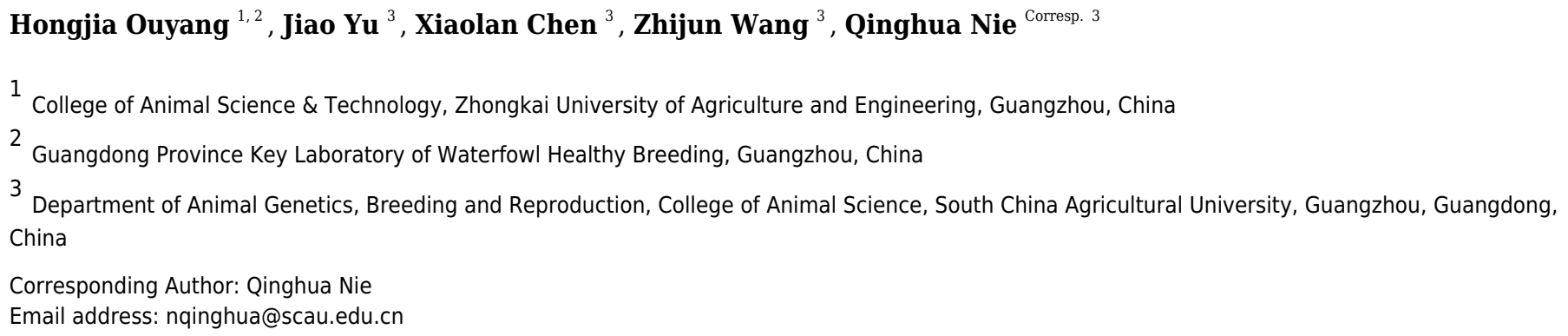

Background. Development of skeletal muscle is closely related to broiler production traits. The myocyte-specific enhancer binding factor (MEF) 2D gene (MEF2D) and its variant transcripts play important parts in myogenesis. Methods. To identify the transcript variants of chicken MEF2D gene and their function, this study cloned chicken MEF2D gene and identified its transcript variants from different tissue samples. The expression levels of different transcripts of MEF2D gene in different tissues and different periods were measured, and their effects on myoblast proliferation and differentiation were investigated. Variations in MEF2D were identified and association analysis with chicken production traits carried out. Results. Four novel transcript variants of MEF2D were obtained, all of which contained highly conserved sequences, including MADS-Box and MEF2-Domain functional regions. Transcript MEF2D-V4 was expressed specifically in muscle, and its expression was increased during embryonic muscle development. The MEF2D-V4 could promote differentiation of chicken myoblasts and its expression was regulated by RBFOX2. The single nucleotide polymorphism (SNP) g.36186C $>$ T generated a TAG stop codon, caused MEF2D-V4 to terminate translation early, and was associated with several growth traits, especially on early body weight. Conclusion. We cloned the musclespecific transcript of MEF2D and preliminarily revealed its role in embryonic muscle development. 
1 A Novel Transcript of MEF2D Promotes Myoblast Differentiation and Its Variations

2 Associated with Growth Traits in Chicken

3

4 Hongjia Ouyang ${ }^{1,3}$, Jiao $\mathrm{Yu}^{2}$, Xiaolan $\mathrm{Chen}^{2}$, Zhijun $\mathrm{Wang}^{2}$, Qinghua $\mathrm{Nie}^{2 *}$

$6 \quad{ }^{1}$ College of Animal Science \& Technology, Zhongkai University of Agriculture and Engineering, 7 Guangzhou 510225, China.

8 2Department of Animal Genetics, Breeding and Reproduction, College of Animal Science, South

9 China Agricultural University, Guangzhou, Guangdong, China. ${ }^{3}$ Guangdong Province Key

10 Laboratory of Waterfowl Healthy Breeding, Guangzhou 510225, China

11

12 *Corresponding author: Qinghua Nie (Tel. 86 20-85285759. Fax.86 20-85280740. E-mail:

13 nqinghua@scau.edu.cn).

14

15 Running head: Chicken MEF2D promotes myoblast differentiation. 


\section{Abstract}

17 Background. Development of skeletal muscle is closely related to broiler production traits. The myocyte-specific enhancer binding factor (MEF) 2D gene $(M E F 2 D)$ and its variant transcripts play important parts in myogenesis.

Methods. To identify the transcript variants of chicken $M E F 2 D$ gene and their function, this study cloned chicken $M E F 2 D$ gene and identified its transcript variants from different tissue samples. The expression levels of different transcripts of $M E F 2 D$ gene in different tissues and different periods were measured, and their effects on myoblast proliferation and differentiation were investigated. Variations in MEF2D were identified and association analysis with chicken 25 production traits carried out.

26 Results. Four novel transcript variants of $M E F 2 D$ were obtained, all of which contained highly

27 conserved sequences, including MADS-Box and MEF2-Domain functional regions. Transcript MEF2D-V4 was expressed specifically in muscle, and its expression was increased during embryonic muscle development. The MEF2D-V4 could promote differentiation of chicken myoblasts and its expression was regulated by $R B F O X 2$. The single nucleotide polymorphism

31 (SNP) g.36186C $>\mathrm{T}$ generated a TAG stop codon, caused MEF2D-V4 to terminate translation 32 early, and was associated with several growth traits, especially on early body weight.

33 Conclusion. We cloned the muscle-specific transcript of $M E F 2 D$ and preliminarily revealed its 34 role in embryonic muscle development.

35 Keywords: chicken; $\quad M E F 2 D ; \quad$ myoblast; $\quad$ variant transcripts; $\quad$ SNP 


\section{Introduction}

Myocyte-specific enhancer binding factor 2 (MEF2) family is present widely in muscle cells. It plays an important role in the development, growth and maintenance of organisms through interacting with various genes in the calcineurin signaling pathway (Potthoff and Olson, 2007). MEF2 is a major regulator of myogenic genes expression, which can activate expression of various myogenic related genes, and interact with members of myogenic regulatory factors (MRFs) to regulate myogenesis (Molkentin et al., 1995; Desjardins et al., 2016). In vertebrates, the MEF2 family has four members, including MEF2A, MEF2B, MEF2C and MEF2D genes. MEF2 belongs to the MADS-Box family of transcription regulators. The N-terminal of the four MEF2 proteins all contain the highly conserved MADS-box domain and MEF2 domain. The structural difference among them is due mainly to the difference in C-terminal transcriptionally active regions (Molkentin et al., 1996; Black et al., 1998). Breitbart et al. first cloned MEF2D in humans, and found that it plays a key role in muscle development (Breitbart et al., 1993). As a member of MEF2 family, $M E F 2 D$ has been reported that plays a key role in myogenesis. In $M E F 2 D$ knockout mice, the differentiation of muscle cells in each muscle tissue was found to be inhibited (Bour et al., 1995; Lilly et al., 1995). The $M E F 2 D$ has also been found to be involved in skeletal myogenesis, cardiac hypertrophic growth and proliferation of vascular smooth muscle cells (Ogawa et al., 2013; Hu et al., 2017; Li et al., 2017).

The chicken MEF2D gene has been cloned, but only one transcript has been reported (Caldwell et al., 2005). In humans and mice, multiple different transcripts of $M E F 2 D$ gene have been found, and these transcripts can perform different functions (Ogawa et al., 2013; Sebastian et al., 2013). In this study, we aim to identify the variant transcripts of chicken $M E F 2 D$ gene from different tissue samples, measure expression levels of these transcripts in various tissues and at different periods, and to study their roles in skeletal myogenesis.

\section{MATERIALS AND METHODS}


61

62

63

64

65

66

67

68

69

\subsection{Animals}

The fertilized eggs of Xinghua chicken in this experiment were purchased from a livestock farm of South China Agricultural University (Guangzhou, China). They were hatched in a fullautomatic incubator. During the period from the 10th embryo age (E10) to the 1st day posthatching (P1), the breast muscle and leg muscle tissues of 20 chickens were collected each day and stored at $-80{ }^{\circ} \mathrm{C}$. Five 7-weeks-old Xinghua female chickens were purchased from a livestock farm of South China Agricultural University. Fifteen tissues (cerebrum, cerebellum, hypothalamus, pituitary, heart, liver, spleen, lung, kidney, breast muscle, leg muscle, subcutaneous fat, abdominal fat, muscular stomach and glandular stomach) of each chicken were collected and stored at $-80{ }^{\circ} \mathrm{C}$.

\subsection{DNA samples}

The DNA samples were obtained from an $\mathrm{F}_{2}$ resource population crossed from Xinghua and White Recessive Rock (XH\&WRR) as described previously (Lei et al., 2005). The population consists of 17 full-sibling families, and $434 \mathrm{~F}_{2}$ individuals (221 male and 213 female chickens) with a detailed record of growth traits, carcass traits, and meat quality traits. Weight (body, semieviscerated, eviscerated, breast muscle, leg muscle and abdominal fat pad) was measured in grams using an electronic scale. The shank length, head width, breast width, breast depth, and body length were measured with vernier caliper. The shank diameter was measured in the middle of the shank with string and straightedge.

\section{$2.3 R N A$ isolation, cDNA synthesis and quantitative real time PCR (qPCR)}

Total RNA of all tissues were isolated using Trizol reagent (Invitrogen, Carlsbad, CA, USA), following the recommended manufacturer's protocol. The quality and quantity of RNA samples were assessed by gel electrophoresis and a spectrophotometer (NanoDrop 2000c; Thermo, Waltham, MA). The cDNA synthesis was performed with $1 \mu \mathrm{g}$ of RNA for each sample 
85 using a RevertAid ${ }^{\mathrm{TM}}$ First Strand cDNA Synthesis Kit (Fementas, Waltham, MA, USA) in a total 86 reaction volume of $20 \mu \mathrm{L}$.

87 The mRNA level of MEF2D and its four variant transcripts, RBFOX2, MHC and MYOD 88 were measured by qPCR. The qPCR was performed using SsoFast Eva Green Supermix (BIO89 RAD, Hercules, USA) in CFX9600 (BIO-RAD). Each sample was assayed in triplicate under the 90 following conditions: $95{ }^{\circ} \mathrm{C}$ for $2 \mathrm{~min}$, followed by 40 cycles of $10 \mathrm{~s}$ at $95{ }^{\circ} \mathrm{C}, 30 \mathrm{~s}$ at the 91 annealing temperature $\left(58-62{ }^{\circ} \mathrm{C}\right), 30 \mathrm{~s}$ at $72{ }^{\circ} \mathrm{C}$, a melt curve by $65^{\circ} \mathrm{C}$ to $95^{\circ} \mathrm{C}$, and increments $920.5^{\circ} \mathrm{C}$ for $5 \mathrm{~s}$. Chicken $G A P D H$ was used as the reference gene for tissue-samples of 7-weeks93 old chickens and myoblasts, whereas $18 S$ rRNA was used as the reference gene for embryonic 94 muscle samples. The relative mRNA level in each sample was calculated using the comparative $952^{-\Delta \Delta \mathrm{Ct}}$ (CT is threshold cycle; $\Delta \Delta \mathrm{Ct}=\Delta \mathrm{Ct}$ target sample $-\Delta \mathrm{Ct}$ control sample) method (Livak and 96 Schmittgen, 2001).

972.4 Gene cloning and sequences analysis

98 Referring to the $M E F 2 D$ gene sequence in chicken (NM_001031600.3) reported by 99 National Center for Biotechnology Information (NCBI), primers were designed to amplify 100 MEF2D gene by PCR. Products of PCR were purified using an Agarose Gel DNA Extraction Kit 101 (Takara, Osaka, Japan) and then cloned into the pMD-18T vector (Takara) according to the 102 manufacturer's protocol. Positive clones were identified by PCR and then sequenced by 103 Invitrogen Co. Ltd (Guangzhou, China).

104 The sequencing results were analyzed and compared with the chicken genome 105 (Gallus_Gallus-5.0/Galgalgal5; http://genome.ucsc.edu/cgi-bin/hgBlat) andMEF2D sequence 106 (NM_001031600.3). DNAStar software (DNASTAR, Madison, WI) was used to analyze the 107 homology of the amino acid (AA) sequence of MEF2D between different species and the 108 conserved regions of the sequence. The amino acid sequences of MEF2D from the other species 109 were obtained from GenBank (Table S1 in file S1). 
110

111

112

113

114

115

116

117

118

119

120

121

122

123

124

125

126

127

128

129

130

131

132

133

\subsection{Plasmid construction, cell culture and transfection}

The coding sequences of chicken $R B F O X 2$ and $M E F 2 D-V 4$ were amplified from cDNA of chicken leg muscle using PCR, and then cloned into the pEGFP-C1 vector (Invitrogen) using the EcoRI and BamHI restriction sites.

Chicken primary myoblasts were isolated from the leg muscle of chickens at 10-11 embryo age as described previously (Luo et al., 2014). Cells were maintained in RPMI-1640 medium (Gibco, Grand Island, NY) supplemented with 20\% (v/v) fetal bovine serum (Gibco), and $100 \mu \mathrm{g} / \mathrm{mL}$ penicillin/streptomycin (Invitrogen) at $37^{\circ} \mathrm{C}$ with $5 \% \mathrm{CO}_{2}$, humidified atmosphere. Cells were seeded in 12 -well plates with $1 \mathrm{~mL}$ per well at $10^{5}$ cells $/ \mathrm{mL}$. When the cells had grown to $70 \%-80 \%$ confluence, they were transfected with plasmids $(1 \mu \mathrm{g} / \mathrm{mL})$ of $M E F 2 D$ or $R B F O X 2$ or $\mathrm{pEGFP}-\mathrm{C} 1$ vector control using lipofectamine 3000 reagent (Invitrogen) according to the manufacturer's instructions.

\subsection{Cell proliferation assay}

After overexpressing $R B F O X 2$ and $M E F 2 D$ genes in myoblasts for $48 \mathrm{~h}$, respectively, cells were collected and fixed with $70 \%$ ethanol overnight at $-20^{\circ} \mathrm{C}$. The fixed cells were collected by centrifugation at $1000 \times \mathrm{g}$, washed once with PBS, and stained with $0.5 \mathrm{~mL}$ propidium iodide (PI) dye solution ( $5 \mathrm{mg}$ PI $+0.1 \mathrm{~mL}$ Triton X-100 $+3.7 \mathrm{mg}$ EDTA $+10 \mathrm{~mL}$ PBS), and then incubate for 30 min at $4^{\circ} \mathrm{C}$ in the dark. After staining, cells were detected by BD FACSAriaII flow cytometer (BD, Franklin Lakes, NJ). The results were analyzed by software ModFit Lt 4.1.

\subsection{Western blotting}

Proteins of transfected myoblasts were extracted using RIPA lysis buffer (Beyotime, Shanghai, China) and the concentration was determined by a bicinchoninic acid (BCA) protein assay kit (Beyotime). The primary antibodies MYOG (1:500 dilution; Biorbyt, Cambridge, UK) and MHC (1:1000 dilution; DSHB, Iowa, USA) were using to measure the protein levels of 
134 MYOG and MHC respectively by Western blotting as described previously (Ouyang et al., 2018).

135 GAPDH (1:1000 dilution; Bioworld, Minnesota, USA) was used as the reference gene.

1362.8 Primers

137 Primers were designed using primer premier 5 software (PREMIER Biosoft, Palo Alto, CA, 138 USA) and synthesized by Bioengineering Co., Ltd. (Shanghai, China). Specific primer sequences 139 are shown in Table S2 and Table S3 in File S1.

$140 \quad 2.9$ Identification and genotyping of SNPS

141 Variations in the coding sequences of chicken MEF2D were identified using PCR with 142 primers PM1-PM9 in our $\mathrm{F}_{2}$ resource population (XH\&WRR). The locations of primers were 143 shown in Figure S1. PCR was performed in $50 \mu \mathrm{L}$ of a mixture containing 50 ng of chicken 144 genomic DNA, 25 pmol of primers and $25 \mu$ L PCR Master Mix (Transgen, Beijing, China), and 145 using the following protocol: $94{ }^{\circ} \mathrm{C}$ for $3 \mathrm{~min}$, followed by 32 cycles of $30 \mathrm{~s}$ at $94{ }^{\circ} \mathrm{C}, 30 \mathrm{~s}$ at the 146 annealing temperature $\left(58-63{ }^{\circ} \mathrm{C}\right), 30 \mathrm{~s}$ at $72{ }^{\circ} \mathrm{C}$ and $72{ }^{\circ} \mathrm{C}$ for $5 \mathrm{~min}$ at last. Twenty DNA

147 samples were selected randomly from the $F_{2}$ resource population (XH\&WRR) for PCR using 148 primers PM1-PM9. PCR products were sequenced by Bioengineering Co., Ltd. (Shanghai, China) 149 and the results were then blasted with each other to identify variations. The special SNPs we 150 were interested were genotyped by PCR and sequencing in all DNA samples of the $\mathrm{F}_{2}$ resource 151 population (XH\&WRR).

\section{2.10 Statistical analysis}

153 SNP frequencies were calculated using the observed numbers of alleles for each SNP. SNP 154 genotypes were tested for Hardy-Weinberg equilibrium (HWE) with the chi-square test. 155 Association analysis of SNPs and fatness traits were performed using the General Linear Models 156 Procedures of SAS 9.0 (SAS Institute Inc., Cary, NC, USA) using the following model: 


$$
Y_{i j k l}=\mu+S_{i}+G_{j}+H_{k}+F_{l}+e_{i j k l}
$$

158 Where $Y=$ the traits phenotypic values; $\mu=$ the overall population mean; $S=$ the effect of gender;

$159 G=$ the effect of genotype; $H=$ the effect of incubation batch; $F=$ the effect of family; $e=$ the

160 random residuals.

161 Data on gene expression were analyzed using SPSS 21.0 (IBM,Amonk, NY, USA). The 162 ANOVA was used to compare expression levels among different groups. All values are 163 presented as means \pm standard error of mean (S.E.M). The threshold for significance was set at $P$ $164<0.05$ and for high significance at $P<0.01$.

\section{2.11 Animal Ethics}

166 Animal experiments were handled in compliance and all efforts were made to minimize 167 suffering. It was approved by the Animal Care Committee of South China Agricultural 168 University (Guangzhou, People's Republic of China) with approval number SCAU\#0014.

\section{3. Results}

170 3.1 Sequence alignment and phylogeny analysis of MEF2D

171 According to the information from NCBI database, the chicken MEF2D gene cDNA 172 sequence (NM_001031600.3) is 4111 bp in length, the coding region is 715-2271nt, and it 173 encodes 518 amino acids (NP_001026771.3). Blast with the chicken genome (GRCg6a/galGal6), 174 this gene is located on chicken chromosome $25(2,742,900-2,782,225)$, the full length of the gene 175 is $39,326 \mathrm{bp}$, and it contains 10 exons and 9 introns.

176 The protein sequences of MEF2D in 10 species (Gallus gallus, Meleagris gallopavo, 177 Coturnix japonica, Homo sapiens, Mus musculus, Rattus norvegicus, Sus scrofa, Bos taurus, 178 Danio rerio and Xenopus laevis) were compared and analyzed by homologous clustering. The 179 results showed that the protein sequences of $M E F 2 D$ were highly conserved, and had conserved 

species tested (Figure 1A). Phylogenetic tree clustering showed that 10 species were divided into

182 four distinct groups: birds (Gallus gallus, Meleagris gallopavo and Coturnix japonica), 183 mammals (Homo sapiens, Mus musculus, Rattus norvegicus, Sus scrofa and Bos taurus), Danio 184 rerio and Xenopus laevis (Figure 1B). Homology between chicken, turkey and quail was more 185 than 96\%. Homology among mammals (human, mouse, rat, pig and cow) was also very high, 186 while the homology between zebrafish and frogs and other species was relatively low (Figure 187 1C).

\subsection{Variant transcripts of chicken MEF2D}

189 In this experiment, cDNA samples from liver, hypothalamus and muscle tissue at different

190 stages were used as PCR templates to clone chicken MEF2D gene, and positively clone PCR

191 products were detected by agarose gel electrophoresis (Figure 2A). Sequencing analysis of PCR

192 products identified four novel variant transcripts (V1-V4) of $M E F 2 D$ (Figure 2B). Compared 193 with the transcript of $M E F 2 D$ gene on NCBI, the transcript V1 (NCBI accession number: 194 KY680649) was 3222 bp in length, had a deletion of 889 bp (1446-2334 nt), and was predicted 195 to encode 251 AA. The transcript V2 (KY680650) was 3616 bp in length, had a deletion of 498 196 bp (1139-1636 nt) and was predicted to encode 353 AA. The transcript V3 (KY680651) was $1974135 \mathrm{bp}$ in length, had an insertion of $21 \mathrm{bp}$ after exon 8 (1570 nt) and an AAC insertion at 1813 198 nt, and was predicted to encode 526 AA. The full length of the transcript V4 (KY680652) was $1994132 \mathrm{bp}$, and a $21 \mathrm{bp}$ is inserted after exon 8 (1570 nt), and was predicted to encode 526 AA.

200 The complete DNA and protein sequences of these four variants are shown in supplementary file $201 \quad$ S2.

Comparative analysis of the amino acid sequences of the four novelMEF2D transcripts 203 V1-V4 revealed that they contained conserved functional MADS-Box and MEF2-Domain. The 204 position and sequence of exon 4 (87-132 AA) of the transcript V4 was different from that of the 
205 other transcripts. This was the same as the variant transcripts found in humans and mice, and

206 they also mutated in the amino acid sequence 87-132 (Figure S2).

207

208

209

210

211

212

213

214

215

216

217

218

219

220

221

222

223

224

225

226

227

228

\subsection{Tissue specific expression of MEF2D}

The expression of MEF2D transcripts in the different tissues of chickens was measured. Two deletion transcripts, $M E F 2 D-V 1$ and $M E F 2 D-V 2$ were barely expressed. The main transcripts expressed were $M E F 2 D-1$ (the same transcription as reported by NCBI), MEF2D-V3 and $M E F 2 D-V 4$. MEF $2 D-1$ and $M E F 2 D-V 3$ were expressed widely in various tissues, and the relative expression levels in adipose tissue and brain tissue were higher, and in the liver and kidney were lower (Figure 3A and 3B). The transcript MEF2D-V4 exhibited muscle-specific expression and was highly expressed in the heart, chest muscles and leg muscles, but its expression in other tissues was extremely low (Figure 3C).We measured expression level of $M E F 2 D-V 4$ in embryonic leg muscles, and found that the expression level of MEF2D-V4 increased from E11 to E19. The expression level of MEF2D-V4 increased significantly at E15 and E17, and it was stably expressed at E17 to E19 (Figure 4).

\subsection{Novel transcript MEF2D-V4 promotes myoblast differentiation in chicken}

The sequence of MEF2D-V4 was similar to that of the human variant transcript Mef2Da2, expression of which was regulated by RBFOX2 and was required for muscle differentiation (Singh et al., 2014; Runfola et al., 2015). Thus, to explore the effects of MEF2D-V4 and RBFOX2 on muscle differentiation, the eukaryotic overexpression vector of $R B F O X 2$ and $M E F 2 D-V 4$ were constructed, and transfected into chicken myoblasts respectively. After $48 \mathrm{~h}$, the expression levels of $R B F O X 2$ and MEF2D-V4 were measured by qPCR: both of these two vectors could induce overexpression of the corresponding genes effectively. Furthermore, overexpression of RBFOX2 gene could also increased the expression level of the MEF2D-V4 significantly (Figure 5). 
After overexpressing MEF2D-V4 and RBFOX2 in chicken primary myoblasts, the cell

230 cycle was detected by flow cytometry. Compared with the control group, the number of S phase

231 cells was increased in overexpressed $M E F 2 D-V 4$ or $R B F O X 2$ group, but did not reach significant

232 levels $(P>0.05$; Figure S3). After overexpressing $M E F 2 D-V 4$ and $R B F O X 2$ for $48 \mathrm{~h}$ in myoblast

233 differentiation, the mRNA level of $M Y O G$ and $M H C$ was both increased $(P<0.05)$ in cells

234 overexpressing $M E F 2 D-V 4$ or $R B F O X 2$, whereas MYOD expression was not significantly

235 different (Figure 6A). The expression of $M Y O G$ and $M H C$ was also detected by Western blot.

236 Protein levels of MYOG and MHC were also increased, in accordance with mRNA levels

237 (Figure 6B).

238

239

240

241

242

243

244

245

246

247

248

249

250

251

252

253

\subsection{SNPs identification and its association analysis with production traits}

In the $\mathrm{F}_{2}$ resource population (XH\&WRR), 31 SNPs were identified in the full length chicken MEF2D DNA through PCR sequencing (Table 1), including one insertion/deletion, 14 synonymous mutations and 16 missense mutations. Interestingly, there was a $\mathrm{T}-\mathrm{C}$ mutation at exon 9, g.36186C > T, generate a TAG stop codon, resulting in a change in the coding sequence and termination of translation in both MEF2D-1and MEF2D-V4. Therefore, we genotyped this SNP by PCR amplification and sequencing on exon 9, and carried out association analysis in the $\mathrm{F}_{2}$ resource population $(\mathrm{XH} \& \mathrm{WRR})$. Several growth traits were associated significantly with this SNP g.36186C > T, including first days, 7, 14, 21, 28 and 63 days of body weight, 42, 77 and 88 days of shank length, 42 and 56 days of shank diameter, and 0-4 weeks of average weight gain (Table 2). The dominant genotype of SNP g.36195C > T was the CC type, and the average early body weight of TT type individuals was lower than that of CC type individuals.

In addition, g.36094CAGIns/Del (another SNP site of exon 9) was associated with carcass traits in chickens (Table 3), including eviscerated weight (EW), leg muscle weight (LMW), abdominal fat pad weight (AFW) and small intestine length (SIL). The dominant genotype of g.36094CAGIns/Del was the Del/del type. EW and LMW of the Del/del type were 
254 lower than that of the Ins/ins type.

\section{4. Discussion}

256

$M E F 2 D$ gene is a member of the MEF2 family and plays a key role in myogenesis (Du et al., 2008; Nebbioso et al., 2009; Della et al., 2012). MEF2D gene has several transcripts in humans and mice, and among them, there are specific transcripts that can have different functions (Ogawa et al., 2013; Sebastian et al., 2013), but only one transcript sequence has been reported in chicken. Therefore, we cloned the variant transcript of the $M E F 2 D$ gene from several different tissues of chicken, and obtained four novel transcripts. Blast analyses of their amino acid sequences revealed that they all contained the conserved functional regions MADS-Box and MEF2-Domain, which conformed to the structural characteristics of the MEF2 family. mice, and they were both mutated in the amino acid sequence 87-132 region (Edmondson et al., 1994; Ornatsky et al., 1996; Nagar et al., 2017). The human variant transcript Mef2Da2 is expressed specifically in muscle, and it can avoid inhibitory phosphorylation, recruit Ash2L to activate muscle-related genes, and promote muscle cell differentiation (Sebastian et al., 2013).

271 Splice variations were also found in mice, producing two transcripts, Mef2Dla and Mef2Dlb.

272 Mef2Dla can promote the expression of $M Y O G$ gene by binding to its promoter, and such 273 binding is regulated by glycosylation (Ogawa et al., 2013). We examined the expression patterns 274 of these four novel transcripts, and found that MEF2D-V4 was also expressed specifically in 275 muscle of the heart, breast and leg. The function of muscle-specific genes is often related to 276 muscle development and growth. During embryonic development, the expression level of $277 M E F 2 D-V 4$ in leg muscle was increased significantly in the late stage embryos, indicating that 278 MEF2D-V4 may play an important role in embryonic muscle development and growth. 
279 Therefore, we studied further the function of $M E F 2 D-V 4$ in chicken primary myoblasts. It has

280 been reported in mice that RBFOX2 regulates alternative splicing of the MEF2D gene (Singh et

281 al., 2014; Runfola et al., 2015). We also found that chicken RBFOX2 promotes the expression of $282 M E F 2 D-V 4$. Overexpression of $R B F O X 2$ and $M E F 2 D-V 4$ promoted the differentiation of 283 chicken myoblasts.

284 Studies have shown that SNPs of MEF2D gene could affect the production performance 285 of livestock and poultry animals. The MEF2D variants have been found to be highly correlated 286 with MEF2D mRNA and protein levels in the longissimus dorsi muscle of cattle (Juszczuk287 Kubiak et al, 2012). In duck, a CAG repeat polymorphism has been found in MEF2D gene. This 288 CAG repeat can generate significantly longer transcription products and positive correlations 289 with five muscle-related traits (Wang et al., 2016b). We also found that a CAG insertion/deletion 290 in MEF2D gene was associated with eviscerated weight and leg muscle weight of chicken. 291 Furthermore, g.36186C $>$ T was found to be associated with body weight at 1, 7, 14, 21 and 28 292 days. This mutation generated a TAG stop codon, caused MEF2D-V4 to terminate translation early, 293 resulting in TT type individuals not being able to produce normal MEF2D-V4 protein products.

294 The average early body weight of TT type individuals was lower than that of CC type individuals, 295 which indicated that MEF2D V4 may be positively correlated with chicken growth traits and 296 promote early growth of chickens.

\section{5. Conclusions}

298 In summary, the $M E F 2 D$ gene can produce the muscle-specific transcript $M E F 2 D-V 4$, 299 which is positively regulated by $R B F O X 2$ and can promote the differentiation of chicken 300 myoblasts. Chicken MEF2D gene could regulate the embryonic development and early growth 301 of skeletal muscle by alternative splicing. 
303

304

305

306

307

308

309

310

311

312

313

314

315

316

317

318

319

320

321

322

323

324

325

326

327

328

\section{References}

Black, B.L., and Olson, E.N. 1998. Transcriptional control of muscle development by myocyte enhancer factor-2 (MEF2) proteins. Annual Review of Cell and Developmental Biology 14:167-196. 10.1146/annurev.cellbio.14.1.167

Bour, B.A., O'Brien, M.A., Lockwood, W.L., Goldstein, E.S., Bodmer, R., Taghert, P.H., Abmayr, S.M., and Nguyen, H.T. 1995. Drosophila MEF2, a transcription factor that is essential for myogenesis. Genes and Development 9:730-741. 10.1101/gad.9.6.730

Breitbart, R.E., Liang, C.S., Smoot, L.B., Laheru, D.A., Mahdavi, V., and Nadal-Ginard, B. 1993. A fourth human MEF2 transcription factor, hMEF2D, is an early marker of the myogenic lineage. Development (Cambridge, England) 118:1095-1106.

Caldwell, R.B., Kierzek, A.M., Arakawa, H., Bezzubov, Y., Zaim, J., Fiedler, P., Kutter, S., Blagodatski, A., Kostovska, D., Koter, M., Plachy, J., Carninci, P., Hayashizaki, Y., and Buerstedde, J.M. 2005. Full-length cDNAs from chicken bursal lymphocytes to facilitate gene function analysis. GENOME BIOLOGY 6:R6. 10.1186/gb-2004-6-1-r6

Della, G.B., Armand, A.S., Lecolle, S., Charbonnier, F., and Chanoine, C. 2012. Mef2d acts upstream of muscle identity genes and couples lateral myogenesis to dermomyotome formation in Xenopus laevis. PLoS One 7:e52359. 10.1371/journal.pone.0052359

Desjardins, C.A., and Naya, F.J. 2016. The Function of the MEF2 Family of Transcription Factors in Cardiac Development, Cardiogenomics, and Direct Reprogramming. Journal of cardiovascular development and disease 3.

Du M, Perry, R.L., Nowacki, N.B., Gordon, J.W., Salma, J., Zhao, J., Aziz, A., Chan, J., Siu, K.W., and McDermott, J.C. 2008. Protein kinase A represses skeletal myogenesis by targeting myocyte enhancer factor 2D. MOLECULAR AND CELLULAR BIOLOGY 28:29522970. 10.1128/MCB.00248-08

Edmondson, D.G., Lyons, G.E., Martin, J.F., and Olson, E.N. 1994. Mef2 gene expression marks the cardiac and skeletal muscle lineages during mouse embryogenesis. 
330 Hu, Z.Q., Luo, J.F., Yu, X.J., Zhu, J.N., Huang, L., Yang, J., Fu, Y.H., Li, T., Xue, Y.M., Feng,

331 Y.Q., and Shan, Z.X. 2017. Targeting myocyte-specific enhancer factor 2D contributes to the 332 suppression of cardiac hypertrophic growth by miR-92b-3p in mice. Oncotarget 8:9207933392089.10 .18632 /oncotarget.20759

334 Juszczuk-Kubiak, E., Starzynski, R.R., Sakowski, T., Wicińska, K., Flisikowski, K. 2012.

335 Effects of New Polymorphisms in the Bovine Myocyte Enhancer Factor 2D (MEF2D) Gene

336 On the Expression Rates of the Longissimus Dorsi Muscle. Molecular Biology Reports 337 39:8387-8393. 10.1007/s11033-012-1689-6.

Li, K., Pan, J., Wang, J., Liu, F., and Wang, L. 2017. MiR-665 regulates VSMCs proliferation 339 via targeting FGF9 and MEF2D and modulating activities of Wnt/beta-catenin signaling. American Journal of Translational Research 9:4402-4414.

341 Lilly, B., Zhao, B., Ranganayakulu, G., Paterson, B.M., Schulz, R.A., and Olson, E.N. 1995.

342 Requirement of MADS Domain Transcription Factor D-MEF2 for Muscle Formation in 343 Drosophila. Science (Washington D C) 267:688-693. 10.1126/science.7839146

344 Livak, K.J., and Schmittgen, T.D. 2001. Analysis of relative gene expression data using real345 time quantitative PCR and the 2-DELTADELTACT method. Methods (Orlando) 25:402-408. $346 \quad 10.1006 /$ meth.2001.1262

347 Luo, W., Wu, H., Ye, Y., Li, Z., Hao, S., Kong, L., Zheng, X., Lin, S., Nie, Q., and Zhang, X. 348 2014. The transient expression of miR-203 and its inhibiting effects on skeletal muscle cell 349 proliferation and differentiation. Cell Death \& Disease 5. 10.1038/cddis.2014.289

350 Molkentin, J.D., Black, B.L., Martin, J.F., and Olson, E.N. 1995. Cooperative activation of 351 muscle gene expression by MEF2 and myogenic bHLH proteins. CELL 83:1125-1136. $352 \quad 10.1016 / 0092-8674(95) 90139-6$

353 Molkentin, J.D., Black, B.L., Martin, J.F., and Olson, E.N. 1996. Mutational analysis of the 354 DNA binding, dimerization, and transcriptional activation domains of MEF2C. 
MOLECULAR AND CELLULAR BIOLOGY 16:2627-2636.

356 Nagar, S., Trudler, D., McKercher, S.R., Pina-Crespo, J., Nakanishi, N., Okamoto, S.I., and

357 Lipton, S.A. 2017. Molecular Pathway to Protection From Age-Dependent Photoreceptor

358 Degeneration in Mef2 Deficiency. Invest Ophthalmol Vis Sci 58:3741-3749. 10.1167/iovs.17$359 \quad 21767$

360 Nebbioso, A., Manzo, F., Miceli, M., Conte, M., Manente, L., Baldi, A., De Luca, A., Rotili, D.,

361 Valente, S., Mai, A., Usiello, A., Gronemeyer, H., and Altucci, L. 2009. Selective class II

362 HDAC inhibitors impair myogenesis by modulating the stability and activity of HDAC-

363 MEF2 complexes. EMBO REPORTS 10:776-782. 10.1038/embor.2009.88

364 Ogawa, M., Sakakibara, Y., and Kamemura, K. 2013. Requirement of decreased O-GlcNAc 365 glycosylation of Mef2D for its recruitment to the myogenin promoter. Biochem Biophys Res 366 Commun 433:558-562. 10.1016/j.bbrc.2013.03.033

367 Ornatsky, O.I., and McDermott, J.C. 1996. MEF2 protein expression, DNA binding specificity 368 and complex composition, and transcriptional activity in muscle and non-muscle cells. 369 JOURNAL OF BIOLOGICAL CHEMISTRY 271:24927-24933.

370

Ouyang, H., Chen, X., Li, W., Li, Z., Nie, Q., and Zhang, X. 2018. Circular RNA circSVIL 371 Promotes Myoblast Proliferation and Differentiation by Sponging miR-203 in Chicken.

372

373

374

375

376

377

378

379

380

Frontiers in Genetics 9:172. 10.3389/fgene.2018.00172

Potthoff, M.J., and Olson, E.N. 2007. MEF2: a central regulator of diverse developmental programs. DEVELOPMENT 134:4131-4140. 10.1242/dev.008367

Runfola, V., Sebastian, S., Dilworth, F.J., and Gabellini, D. 2015. Rbfox proteins regulate tissue-specific alternative splicing of Mef2D required for muscle differentiation. JOURNAL OF CELL SCIENCE 128:631-637. 10.1242/jcs.161059

Sebastian, S., Faralli, H., Yao, Z., Rakopoulos, P., Palii, C., Cao, Y., Singh, K., Liu, Q., Chu, A., Aziz, A., Brand, M., Tapscott, S.J., and Dilworth, F.J. 2013. Tissue-specific splicing of a ubiquitously expressed transcription factor is essential for muscle differentiation. GENES \& 
381 DEVELOPMENT 27:1247-1259. 10.1101/gad.215400.113

382 Singh, R.K., Xia, Z., Bland, C.S., Kalsotra, A., Scavuzzo, M.A., Curk, T., Ule, J., Li, W., and 383 Cooper, T.A. 2014. Rbfox2-coordinated alternative splicing of Mef2d and Rock2 controls 384 myoblast fusion during myogenesis. MOLECULAR CELL 55:592-603. $385 \quad 10.1016 / \mathrm{j}$. molcel.2014.06.035

386 Wang, Y., Wang, J., Liu, H., Zhang, R., Zhang, T., Gan, X., Huang, H., Chen, D., Li, L. 2016. 387 Discovery, Characterization, and Functional Study of a Novel MEF2D CAG Repeat in Duck 388 (Anas platyrhynchos). DNA and Cell Biology 35:398-409. 10.1089/dna.2016.3222. 


\section{Figure Legends}

391 Figure 1. Analysis of MEF2D protein sequence. (A) The highly conserved functional region of

392 the MEF2D protein sequence. (B) Clustering analysis of MEF2D protein sequences in ten

393 different species. (C) Homology analysis of MEF2D protein sequences in ten different species.

394 Figure 2. Gene structures of various transcripts of chicken MEF2D. (A) PCR amplification 395 results of MEF2D gene cloning. (B) Gene structures of four novel transcripts. UTR: un396 translated region; CDS: coding DNA sequence; In/Del: Insertion/deletion.

397 Figure 3. The expression pattern of different MEF2D variants in various tissues of chicken. 398 Cer, cerebrum; Ceb, cerebellum; Hyp, hypothalamus; Pit, pituitary; Hea, heart; Liv, liver; Spl, 399 spleen; Lun, lung; Kid, kidney; Brm, breast muscle; Lem, leg muscle; Abf, abdominal fat; Suf, 400 subcutaneous fat; Mus, muscular stomach; Gls, glandular stomach.

401 Figure 4. Expression patterns of MEF2D-V4 in leg muscle at different stage. Different 402 uppercase letters on the error bar indicated extremely significant differences $(P<0.01)$, different 403 lowercase letters indicated significant differences $(P<0.05)$, while the same letters show no 404 significant differences $(P>0.05)$.

405 Figure 5. Overexpression of MEF2D and RBFOX2 in chicken myoblast. OV-MEF2D-V4 406 indicates overexpression vector of MEF2D-V4, OV-RBFOX2 indicates overexpression vector of 407 RBFOX2, EGFP control indicates control vector of pEGFP-C1. **P $<0.01$.

408 Figure 6. Chicken MEF2D promotes primary myoblast differentiation. (A) The expression 409 of MYOG and MHC was determined by qPCR in primary myoblast after overexpressed MEF2D 410 and RBFOX2. (B) The expression of MYOG and MHC was determined by Western blotting in 411 primary myoblast after overexpressed MEF2D and RBFOX2. OV-MEF2D-V4 or OV-M 412 indicates overexpression vector of MEF2D-V4, OV-RBFOX2 or OV-R indicates overexpression 413 vector of RBFOX2, EGFP control or NC indicates control vector of pEGFP-C1. $* P<0.05$. 


\section{Figure 1}

Figure 1. Analysis of MEF2D protein sequence.

(A) The highly conserved functional region of the MEF2D protein sequence. (B) Clustering analysis of MEF2D protein sequences in ten different species. (C) Homology analysis of MEF2D protein sequences in ten different species. 


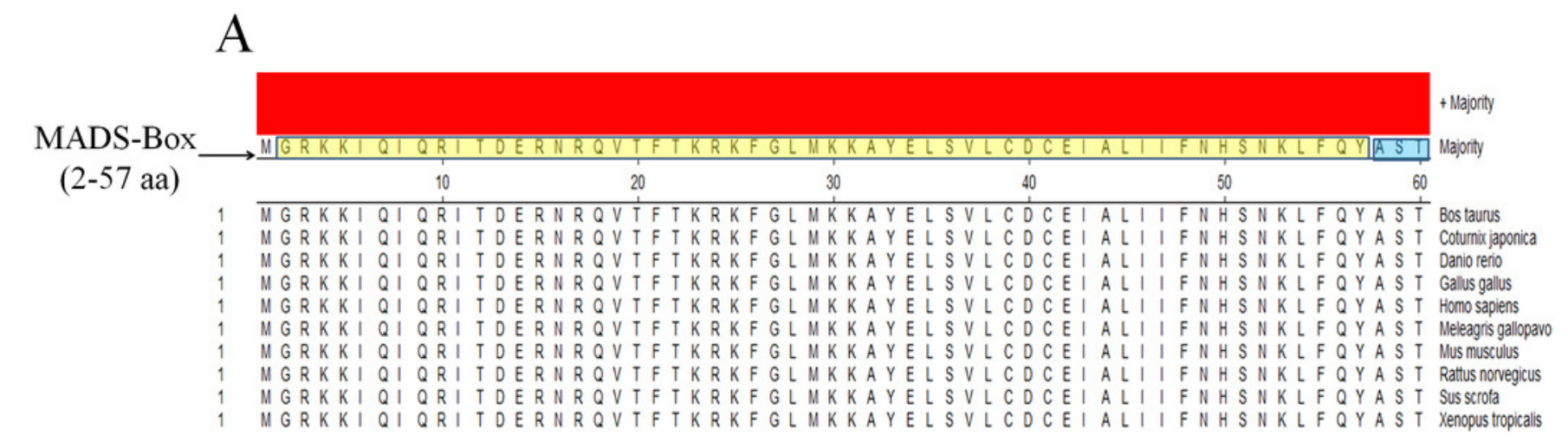

MEF2-domain

(58-86 aa)

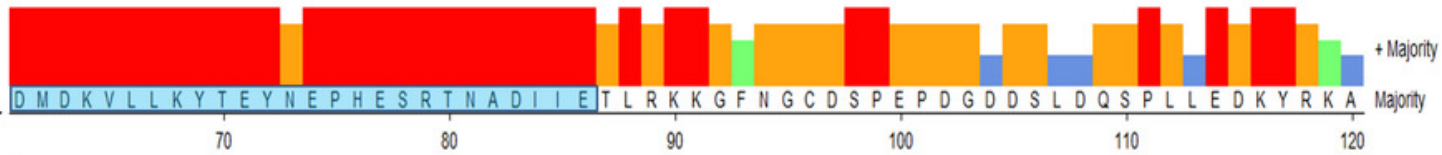

DMDKVLLKYTEYNEPHESRTNADI IETLRKKGFNGCDSPEPDGEDSLEOSPLLEOKYRRA BOSTaUns

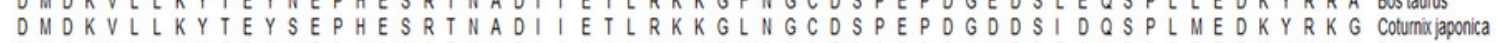

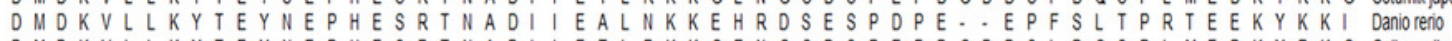

D M DKVLLKY TEYNEPHESRTNADI I ETLRKKGFNGCDSPEPDGDDSIDQSPLMEDKYRKG Galusgallus

D M D KVLLKY TEYNEPHESRTNADIIETLRKKGFNGCDSPEPDGEDSLE QSPLLEDKYRRA Homosapiens

D M D K V LLKYTEYNEPHESRTNA DIIETLRKKGFNGCDSPEPDGDDSIDQSPLMEDKYRKG Meleagris gallopavo

D M DKVLLKY TEYNEPHESRTNADIIETLRKKGFNGCDSPEPDGEDSLEQSPLLEDKYRRA MUSmusculus

D M DKVLLKYTEYNEPHESRTNADIIETLRKKGFNGCDSPEPDGEDSLEQSPLLEDKYRRA Ratus NONegicus

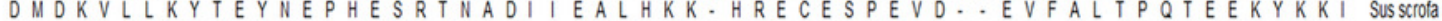

D M D KVLLKYTEYNEPHESRTNADI I ETLRKKGFNGCDSPEPDGDDSIDQSPLMEDKYRKA Xenopustropicalis

B

B

- Mus musculus

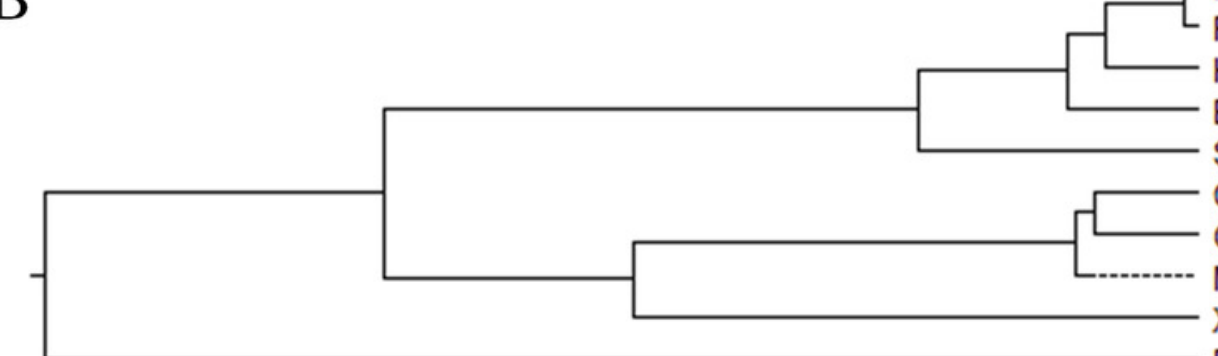

18.1

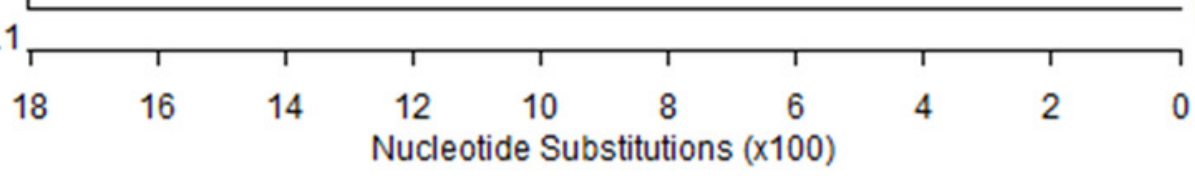

Rattus norvegicus

Homo sapiens

Bos taurus

Sus scrofa

Coturnix japonica

Gallus gallus

Meleagris gallopavo

Xenopus tropicalis

Danio rerio

Nucleotide Substitutions (x100)

C

Percent Identity

\begin{tabular}{|c|c|c|c|c|c|c|c|c|c|c|c|}
\hline & 1 & 2 & 3 & 4 & 5 & 6 & 7 & 8 & 9 & 10 & \\
\hline 1 & & 76.7 & 65.5 & 76.1 & 96.4 & 77.7 & 94.9 & 94.9 & 90.3 & 75.0 & 1 \\
\hline 2 & 24.9 & & 68.5 & 96.7 & 78.4 & 98.5 & 76.9 & 77.1 & 73.7 & 82.5 & 2 \\
\hline 3 & 38.9 & 34.0 & & 67.0 & 65.1 & 69.2 & 64.9 & 64.9 & 69.2 & 69.4 & 3 \\
\hline 4 & 26.5 & 3.2 & 36.0 & & 76.4 & 97.1 & 75.7 & 75.9 & 72.1 & 81.0 & 4 \\
\hline 5 & 3.6 & 22.8 & 37.8 & 24.2 & & 78.7 & 96.8 & 96.8 & 91.2 & 76.8 & 5 \\
\hline 6 & 24.3 & 1.6 & 33.3 & 2.8 & 22.2 & & 77.3 & 77.5 & 73.3 & 83.5 & 6 \\
\hline 7 & 4.5 & 24.6 & 38.9 & 26.3 & 2.8 & 24.1 & & 99.6 & 89.5 & 75.2 & 7 \\
\hline 8 & 4.5 & 24.4 & 38.9 & 26.0 & 2.8 & 23.8 & 0.4 & & 89.5 & 75.0 & 8 \\
\hline 9 & 8.6 & 28.7 & 31.6 & 30.7 & 7.7 & 28.4 & 9.3 & 9.3 & & 71.4 & 9 \\
\hline \multirow[t]{2}{*}{10} & 25.4 & 17.0 & 36.0 & 18.6 & 24.5 & 16.0 & 24.9 & 24.9 & 29.2 & & 10 \\
\hline & 1 & 2 & 3 & 4 & 5 & 6 & 7 & 8 & 9 & 10 & \\
\hline
\end{tabular}

Bos taurus

Coturnix japonica

Danio rerio

Gallus gallus

Homo sapiens

Meleagris gallopavo

Mus musculus

Rattus norvegicus

Sus scrofa

Xenopus tropicalis 
Figure 2

Figure 2. Gene structures of various transcripts of chicken MEF2D.

(A) PCR amplification results of MEF2D gene cloning. (B) Gene structures of four novel transcripts. UTR: un-tranlated region; CDS: coding DNA sequence; In/Del: Insertion/deletion.

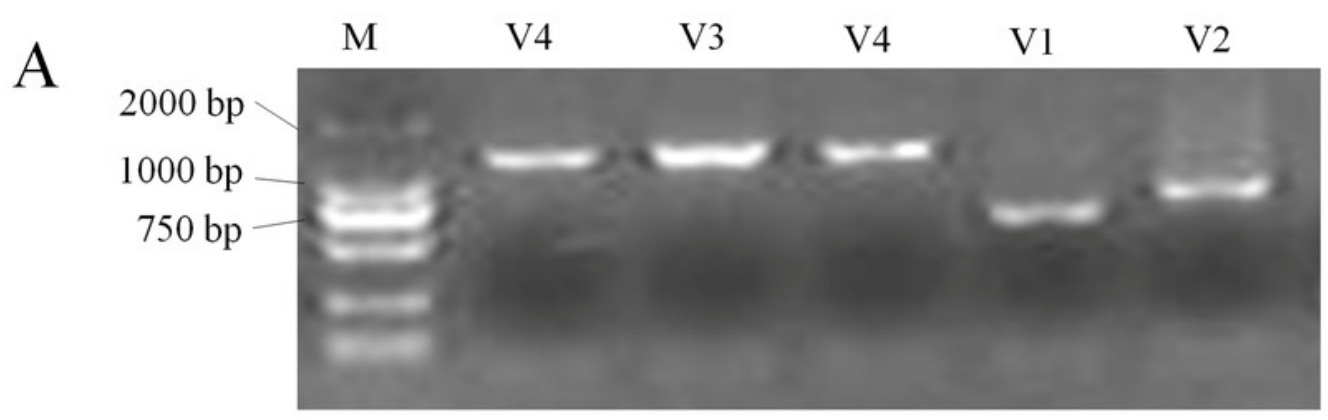

B chr25:2,742,900-2,782,225

$\square$ ''UTR $\square$ CDS $\square$ 3'UTR

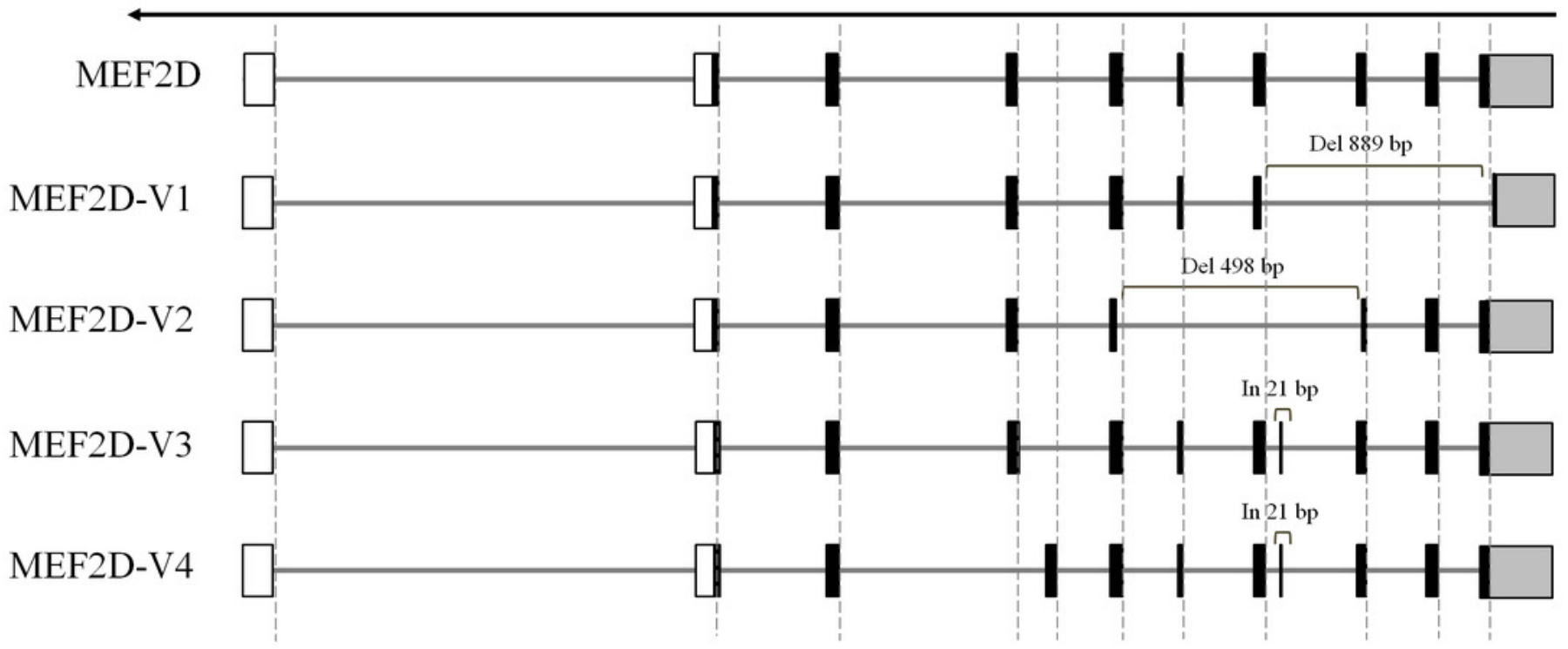


Figure 3

Figure 3. The expression pattern of different MEF2D variants in various tissues of chicken.

Cer, cerebrum; Ceb, cerebellum; Hyp, hypothalamus; Pit, pituitary; Hea, heart; Liv, liver; Spl, spleen; Lun, lung; Kid, kidney; Brm, breast muscle; Lem, leg muscle; Abf, abdominal fat; Suf, subcutaneous fat; Mus, muscular stomach; Gls, glandular stomach. 


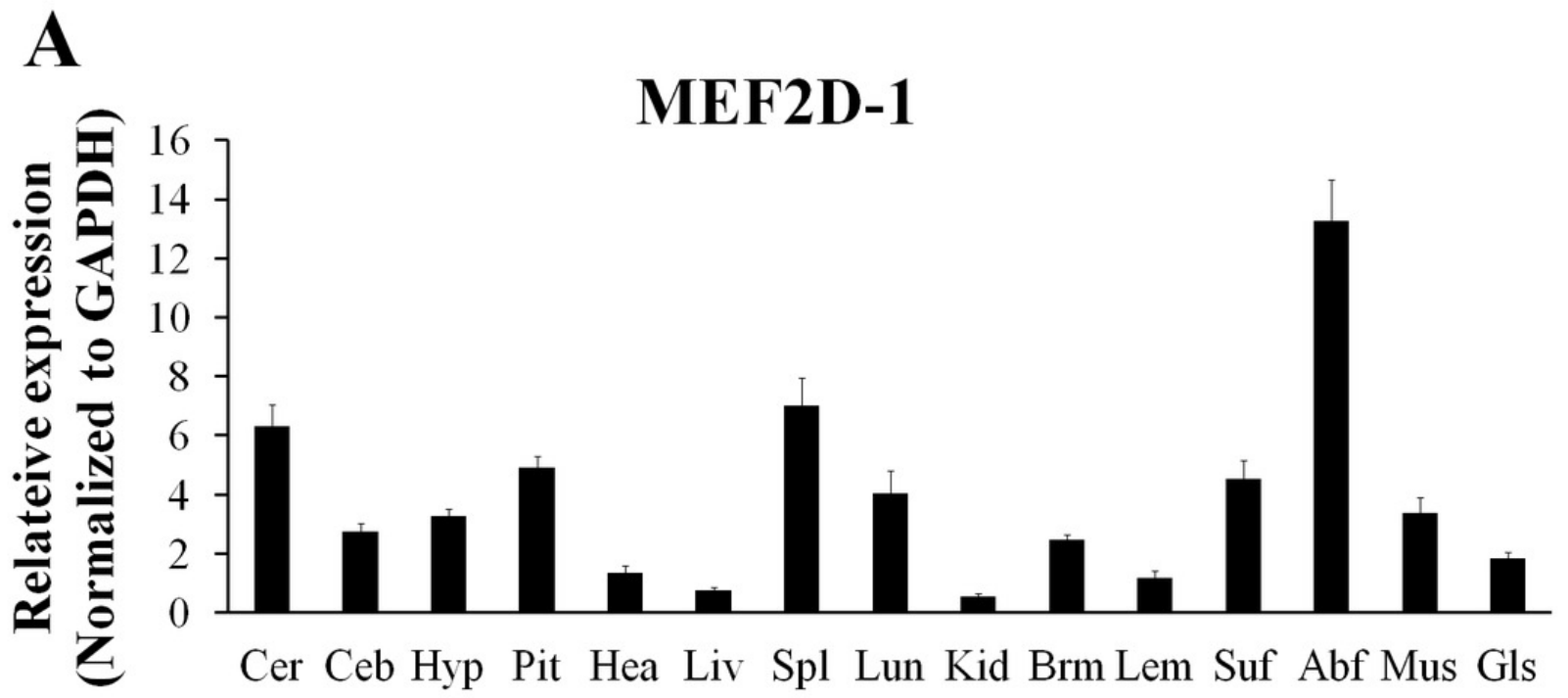

B

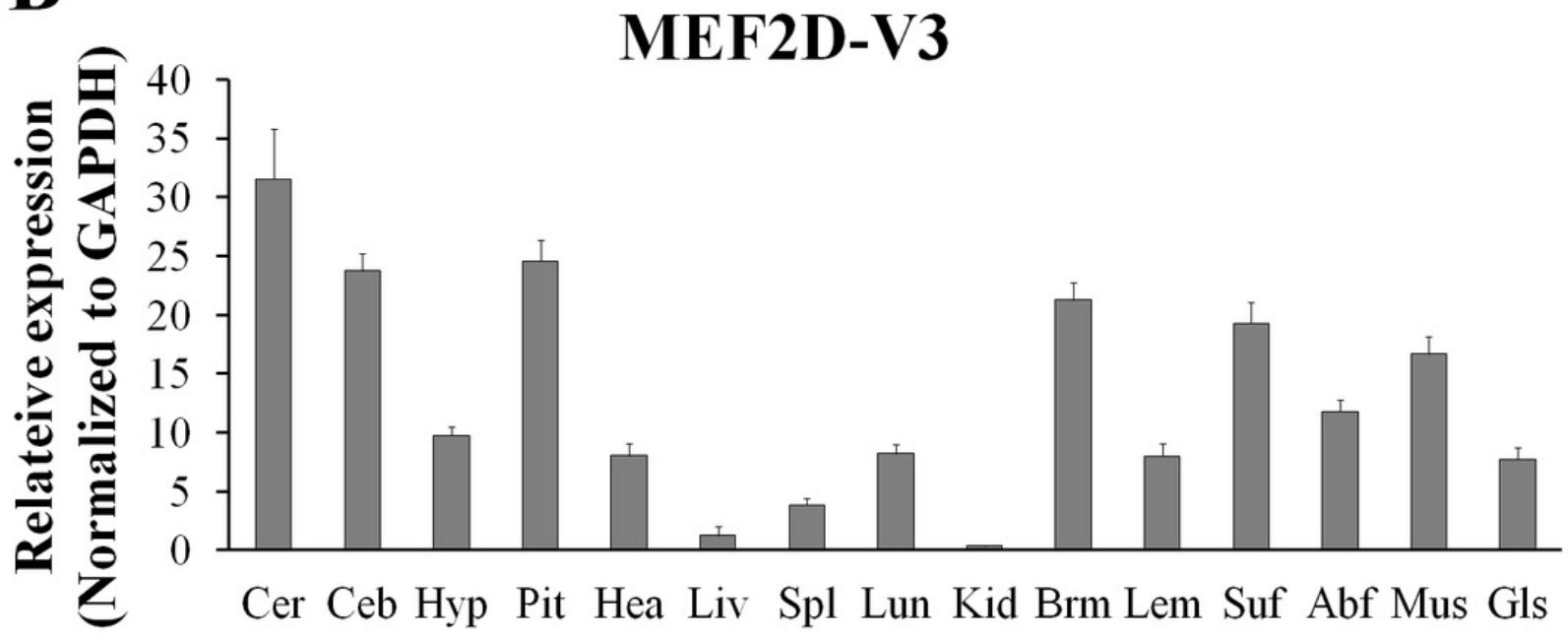

C

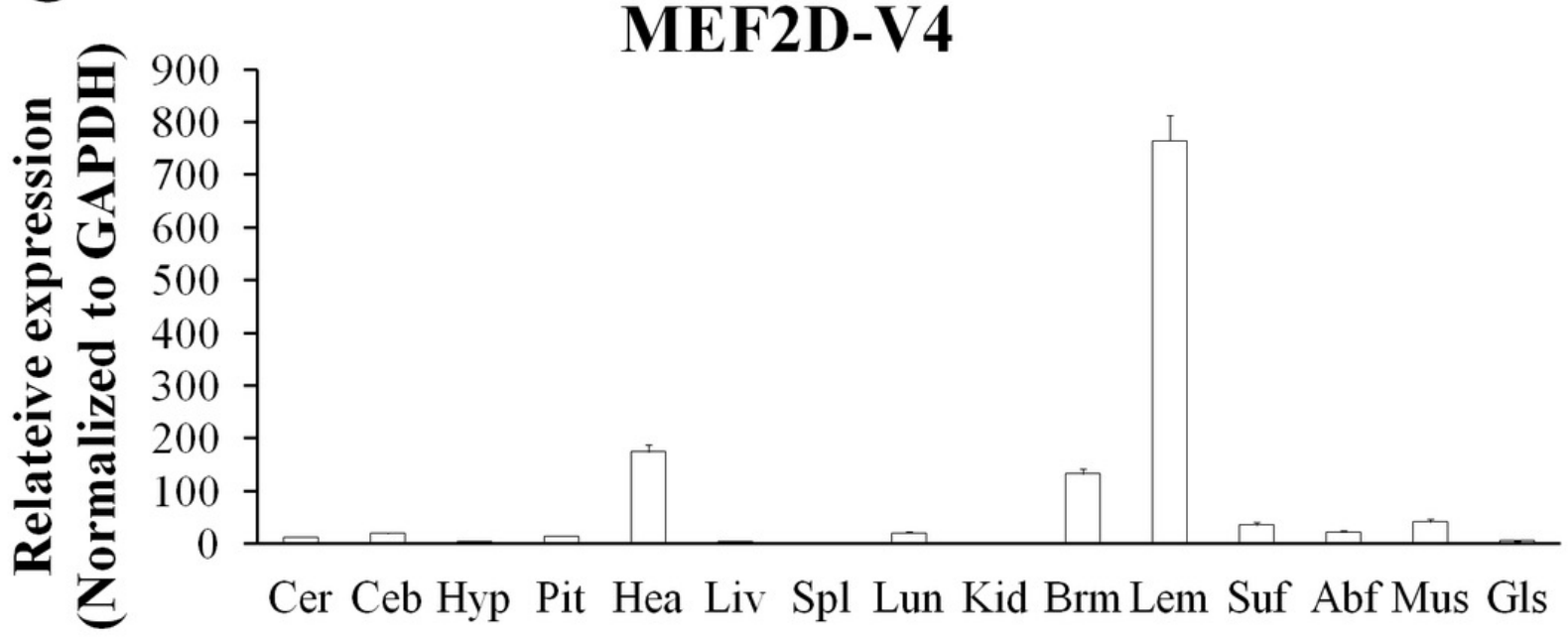


Figure 4

Figure 4. Expression patterns of MEF2D-V4 in leg muscle at different stage.

Different uppercase letters on the error bar indicated extremely significant differences $(\mathrm{P}<$ $0.01)$, different lowercase letters indicated significant differences $(P<0.05)$, while the same letters show no significant differences $(P>0.05)$.

\section{MEF2D-V4}

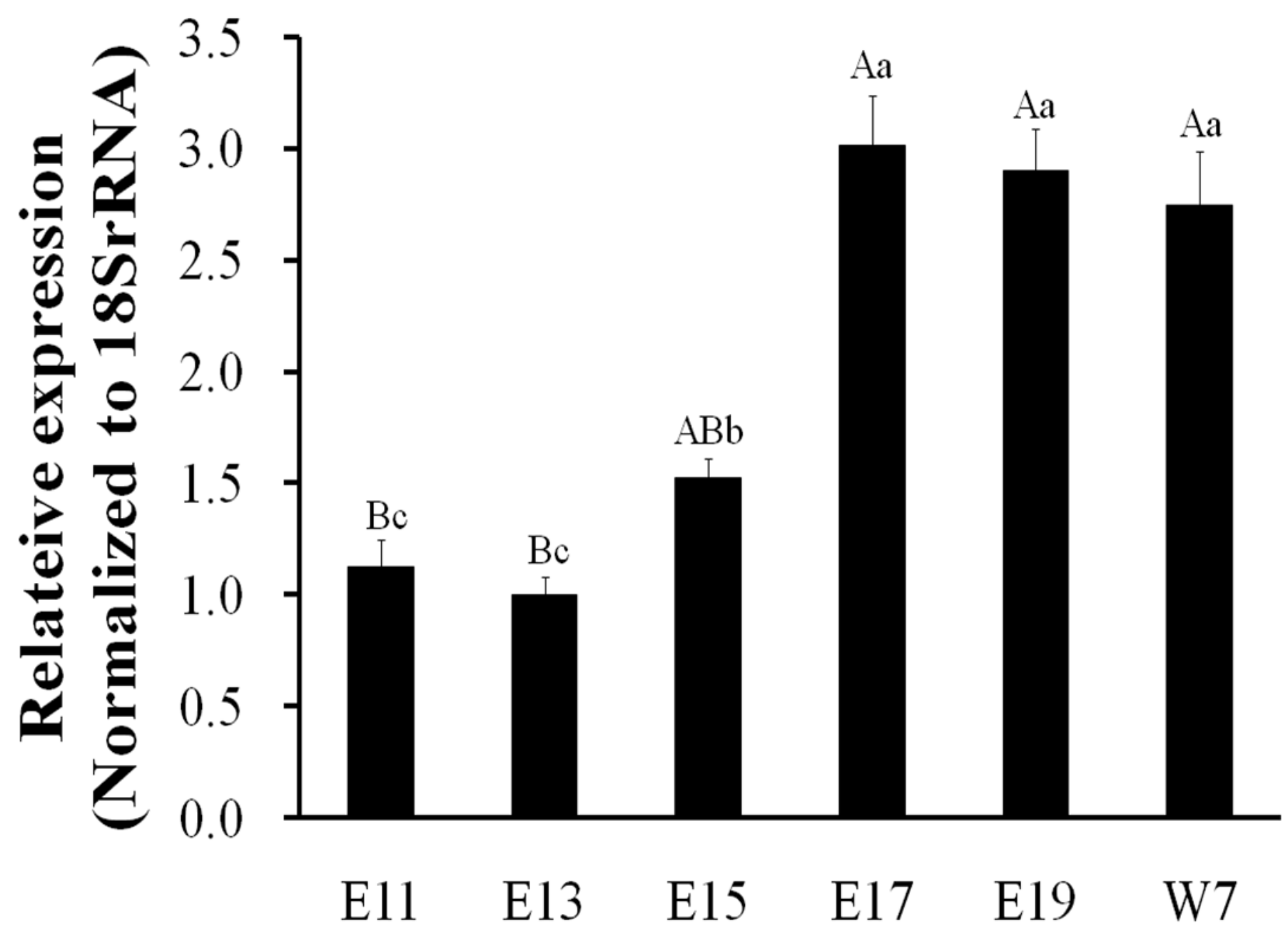


Figure 5

Figure 5. Overexpression of MEF2D and RBFOX2 in chicken myoblast.

OV-MEF2D-V4 indicates overexpression vector of MEF2D-V4, OV-RBFOX2 indicates overexpression vector of RBFOX2, EGFP control indicates control vector of pEGFP-C1. ${ }^{* * P}<$ 0.01 .

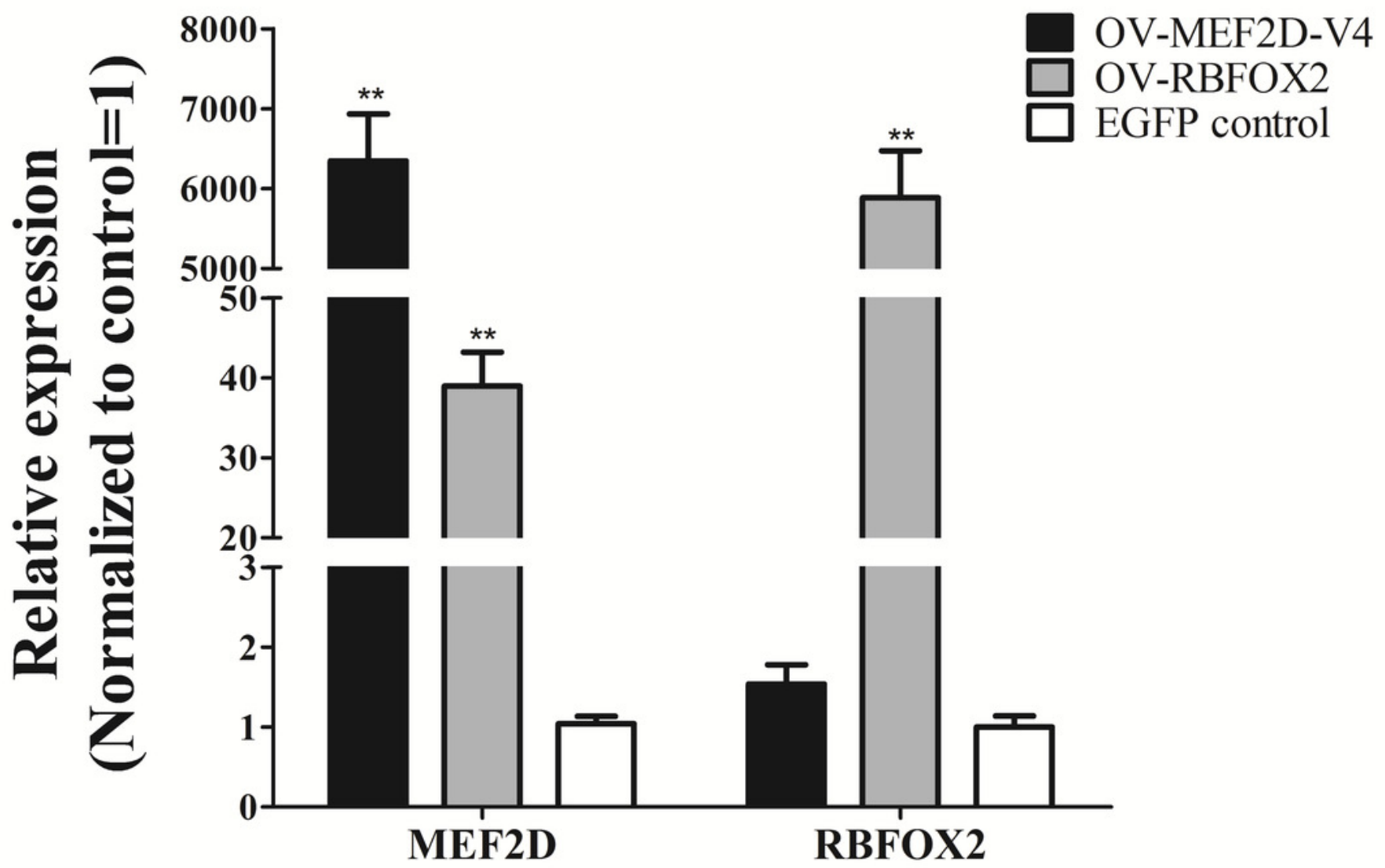




\section{Figure 6}

Figure 6. Chicken MEF2D promotes primary myoblast differentiation.

(A) The expression of MYOG and MHC was determined by QPCR in primary myoblast after

overexpressed MEF2D and RBFOX2. (B) The expression of MYOG and MHC was determined by Western blotting in primary myoblast after overexpressed MEF2D and RBFOX2. OVMEF2D-V4 or OV-M indicates overexpression vector of MEF2D-V4, OV-RBFOX2 or OV-R indicates overexpression vector of RBFOX2, EGFP control or NC indicates control vector of pEGFP-C1. *P $<0.05$. 


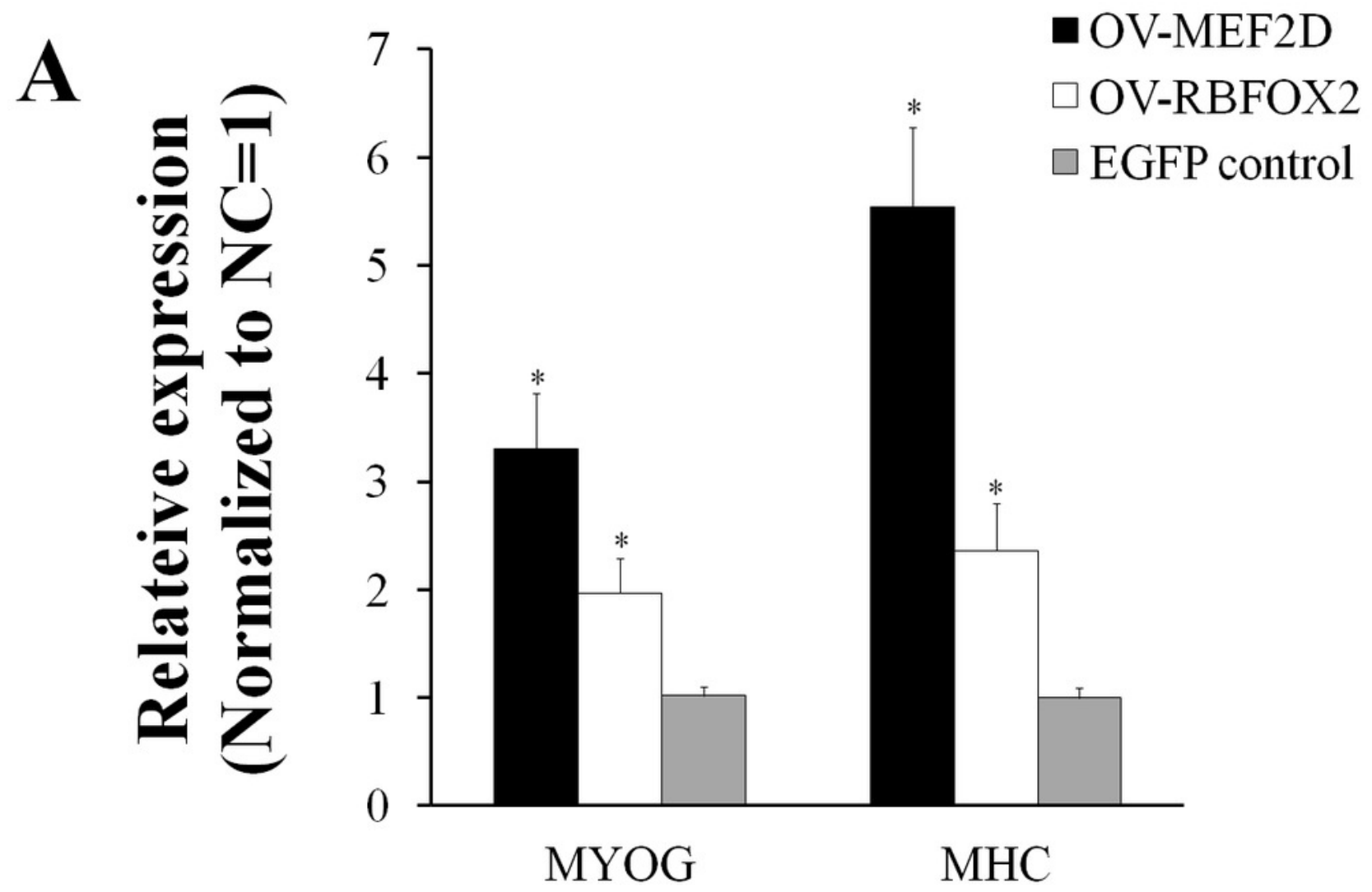

B
OV-M
NC
OV-R

MYOG

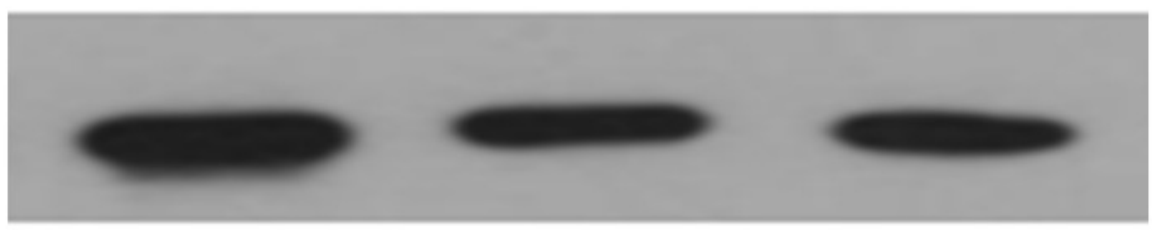

MHC

GAPDH 


\section{Table 1 (on next page)}

Table 1. SNPs in the chicken MEF2D gene. 
1 Table 1. SNPs in the chicken MEF2D gene.

\begin{tabular}{|c|c|c|c|}
\hline SNP name & $\begin{array}{l}\text { Site in the } \\
\text { gene }\end{array}$ & Mutation type & Note \\
\hline g. $26427 \mathrm{~T}>\mathrm{G}$ & exon5 & missense & Thr/Pro \\
\hline g. $26446 \mathrm{G}>\mathrm{T}$ & exon5 & missense & Pro/Asn \\
\hline g. $26501 G>A$ & exon5 & synonymous & \\
\hline g. $26561 \mathrm{~T}>\mathrm{G}$ & exon5 & synonymous & \\
\hline g. $26564 \mathrm{C}>\mathrm{G}$ & exon5 & missense & $\mathrm{Gln} / \mathrm{His}$ \\
\hline g. $26590 \mathrm{~A}>\mathrm{C}$ & exon5 & missense & Val/Gly \\
\hline g. $26608 \mathrm{~T}>\mathrm{G}$ & exon5 & missense & Gln/Pro \\
\hline g. $26621 \mathrm{~A}>\mathrm{C}$ & exon5 & missense & Ser/Arg \\
\hline g. $28390 \mathrm{C}>\mathrm{T}$ & exon6 & synonymous & \\
\hline g. $28405 \mathrm{G}>\mathrm{A}$ & exon6 & synonymous & \\
\hline g. $28423 \mathrm{~T}>\mathrm{C}$ & exon6 & synonymous & \\
\hline g. $30792 \mathrm{~A}>\mathrm{G}$ & exon7 & missense & Ser/Pro \\
\hline g.30808G $>$ A & exon7 & missense & Pro/Leu \\
\hline g. $30852 \mathrm{~A}>\mathrm{T}$ & exon7 & missense & Ser/Thr \\
\hline g. $30857 \mathrm{~A}>\mathrm{G}$ & exon7 & synonymous & \\
\hline g. $30860 \mathrm{C}>\mathrm{G}$ & exon7 & synonymous & \\
\hline g. $30866 \mathrm{~T}>\mathrm{G}$ & exon7 & synonymous & \\
\hline g. $30888 \mathrm{~A}>\mathrm{G}$ & exon7 & missense & Ser/Pro \\
\hline g. $30892 \mathrm{~T}>\mathrm{G}$ & exon7 & missense & Asn/Thr \\
\hline g. $30921 \mathrm{~T}>\mathrm{G}$ & exon7 & missense & Thr/Pro \\
\hline g.33959C > G & exon8 & missense & Ala/Pro \\
\hline g. $36092 \mathrm{~A}>\mathrm{G}$ & exon9 & synonymous & \\
\hline g.36094CAGIns/Del & exon9 & Insert/Delete & \\
\hline g. $36137 \mathrm{~A}>\mathrm{G}$ & exon9 & synonymous & \\
\hline g. $36176 \mathrm{~A}>\mathrm{G}$ & exon9 & synonymous & \\
\hline g. $36179 A>G$ & exon9 & synonymous & \\
\hline g. $36186 \mathrm{C}>\mathrm{T}$ & exon9 & missense & Gln/stop \\
\hline g. $37162 \mathrm{~T}>\mathrm{C}$ & exon 10 & synonymous & \\
\hline g. $37187 \mathrm{~T}>\mathrm{G}$ & exon 10 & missense & Thr/Pro \\
\hline
\end{tabular}




\begin{tabular}{lccc}
\hline g.37270T $>$ G & exon10 & synonymous & \\
g.37287T $>$ G & exon10 & missense & His/Pro \\
\hline
\end{tabular}

2 
Table 2 (on next page)

Table 2. SNP g.36186C > T associated with growth traits in chicken 
1 Table 2. SNP g.36186C $>\mathrm{T}$ associated with growth traits in chicken

\begin{tabular}{|c|c|c|c|c|}
\hline \multirow{2}{*}{$\frac{\text { Traits }}{\text { BW1 (g) }}$} & \multirow{2}{*}{$\frac{P \text {-value }}{0.0001}$} & \multicolumn{3}{|c|}{ Least-mean-squares \pm s.e.m } \\
\hline & & $26.59 \pm 0.64^{\mathrm{C}}$ & $28.84 \pm 5.05^{\mathrm{B}}$ & $29.91 \pm 0.16^{\mathrm{A}}$ \\
\hline & & $(\mathrm{TT}, 15)$ & $(\mathrm{TC}, 56)$ & $(\mathrm{CC}, 251)$ \\
\hline \multirow[t]{2}{*}{ BW7 (g) } & 0.0004 & $54.90 \pm 2.48^{\mathrm{AB}}$ & $55.08 \pm 1.17^{\mathrm{B}}$ & $59.85 \pm 0.54^{\mathrm{A}}$ \\
\hline & & $(\mathrm{TT}, 15)$ & $(\mathrm{TC}, 56)$ & $(\mathrm{CC}, 251)$ \\
\hline \multirow[t]{2}{*}{ BW14 (g) } & 0.0001 & $116.62 \pm 4.61^{\mathrm{AB}}$ & $113.80 \pm 2.39^{\mathrm{B}}$ & $125.44 \pm 1.13^{\mathrm{A}}$ \\
\hline & & $(\mathrm{TT}, 15)$ & $(\mathrm{TC}, 56)$ & $(\mathrm{CC}, 251)$ \\
\hline \multirow[t]{2}{*}{ BW21 (g) } & 0.0007 & $193.15 \pm 8.25^{\mathrm{ABb}}$ & $195.66 \pm 4.35^{\mathrm{Bb}}$ & $221.01 \pm 2.05^{\mathrm{Aa}}$ \\
\hline & & $(\mathrm{TT}, 15)$ & $(\mathrm{TC}, 56)$ & $(\mathrm{CC}, 251)$ \\
\hline \multirow[t]{2}{*}{ BW28 (g) } & 0.0064 & $294.51 \pm 11.95^{\mathrm{AB}}$ & $291.62 \pm 6.19^{\mathrm{B}}$ & $312.22 \pm 2.94^{\mathrm{A}}$ \\
\hline & & $(\mathrm{TT}, 15)$ & $(\mathrm{TC}, 56)$ & $(\mathrm{CC}, 251)$ \\
\hline \multirow[t]{2}{*}{ BW63 (g) } & 0.0264 & $949.07 \pm 40.02^{\mathrm{ab}}$ & $965.01 \pm 23.14^{b}$ & $1023.99 \pm 11.65^{\mathrm{a}}$ \\
\hline & & $(\mathrm{TT}, 15)$ & $(\mathrm{TC}, 56)$ & $(\mathrm{CC}, 251)$ \\
\hline \multirow[t]{2}{*}{$\mathrm{SL} 42(\mathrm{~mm})$} & 0.0159 & $59.38 \pm 1.07^{\mathrm{AB}}$ & $59.20 \pm 0.58^{\mathrm{B}}$ & $60.90 \pm 0.26^{\mathrm{A}}$ \\
\hline & & $(\mathrm{TT}, 15)$ & $(\mathrm{TC}, 52)$ & $(\mathrm{CC}, 248)$ \\
\hline \multirow[t]{2}{*}{ SL77(mm) } & 0.0417 & $84.23 \pm 1.67^{b}$ & $88.34 \pm 1.06^{\mathrm{a}}$ & $88.80 \pm 0.60^{\mathrm{a}}$ \\
\hline & & $(\mathrm{TT}, 9)$ & $(\mathrm{TC}, 23)$ & $(\mathrm{CC}, 69)$ \\
\hline \multirow[t]{2}{*}{ SL84(mm) } & 0.0465 & $86.95 \pm 1.81^{\mathrm{ab}}$ & $90.96 \pm 0.95^{\mathrm{a}}$ & $88.63 \pm 0.43^{\mathrm{b}}$ \\
\hline & & $(\mathrm{TT}, 9)$ & $(\mathrm{TC}, 33)$ & $(\mathrm{CC}, 157)$ \\
\hline \multirow[t]{2}{*}{$\mathrm{SD} 42(\mathrm{~mm})$} & 0.0069 & $7.75 \pm 0.17^{\mathrm{AB}}$ & $7.56 \pm 0.093^{\mathrm{B}}$ & $7.89 \pm 0.043^{\mathrm{A}}$ \\
\hline & & $(\mathrm{TT}, 15)$ & $(\mathrm{TC}, 52)$ & $(\mathrm{CC}, 248)$ \\
\hline \multirow[t]{2}{*}{$\mathrm{SD} 56(\mathrm{~mm})$} & 0.014 & $8.63 \pm 0.20^{\mathrm{AB}}$ & $8.47 \pm 0.10^{\mathrm{B}}$ & $8.79 \pm 0.049^{\mathrm{A}}$ \\
\hline & & $(\mathrm{TT}, 15)$ & $(\mathrm{TC}, 56)$ & $(\mathrm{CC}, 248)$ \\
\hline $0-4 \mathrm{Wks}$ & 0.0149 & $9.57 \pm 0.42^{\mathrm{AB}}$ & $9.38 \pm 0.22^{\mathrm{B}}$ & $10.07 \pm 0.10^{\mathrm{A}}$ \\
\hline $\operatorname{ADG}(\mathrm{g} / \mathrm{w})$ & & $(\mathrm{TT}, 15)$ & $(\mathrm{TC}, 56)$ & $(\mathrm{CC}, 251)$ \\
\hline
\end{tabular}

2 Note: BW, body weight; SL, shank length; SD, shank diameter; 0-4WKs ADG (g/w), 0-4 weeks of

3 average weight gain (g/week). Letters and numbers in bracket refer to genotype and number of chickens 
4 with that genotype. ${ }^{\mathrm{a}, \mathrm{b}} P<0.05 ;{ }^{\mathrm{A}, \mathrm{B}} P<0.01$. 


\section{Table 3 (on next page)}

Table 3. SNP g.36094CAGIns/Del associated with carcass traits in chicken 
1 Table 3. SNP g.36094CAGIns/Del associated with carcass traits in chicken

\begin{tabular}{ccccc}
\hline Traits & $P$-value & \multicolumn{3}{c}{ Least-mean-squares \pm s.e.m } \\
\hline EW (g) & 0.0042 & $1093.2 \pm 107.3^{\mathrm{A}}$ & $1075.5 \pm 114.2^{\mathrm{AB}}$ & $1024.9 \pm 102.5^{\mathrm{B}}$ \\
& & $(\mathrm{Ins} / \mathrm{ins}, 62)$ & $(\mathrm{Ins} / \mathrm{del}, 80)$ & $(\mathrm{Del} / \mathrm{del}, 160)$ \\
LMW (g) & 0.013 & $119.5 \pm 13.2^{\mathrm{a}}$ & $117.4 \pm 14.3^{\mathrm{a}}$ & $112.6 \pm 10.8^{\mathrm{b}}$ \\
& & $($ Ins/ins, 62) & $($ Ins/del, 80) & $(\mathrm{Del} / \mathrm{del}, 160)$ \\
$\mathrm{AFW}(\mathrm{g})$ & 0.021 & $24.33 \pm 2.54^{\mathrm{b}}$ & $28.92 \pm 4.24^{\mathrm{a}}$ & $26.91 \pm 4.16^{\mathrm{ab}}$ \\
& & $(\mathrm{Ins} / \mathrm{ins}, 54)$ & $($ Ins/del, 69) & $(\mathrm{Del} / \mathrm{del}, 142)$ \\
SIL $(\mathrm{mm})$ & 0.028 & $133.6 \pm 15.4^{\mathrm{ab}}$ & $149.5 \pm 11.5^{\mathrm{a}}$ & $136.2 \pm 10.2^{\mathrm{b}}$ \\
& & $($ Ins/ins, 50) & $($ Ins/del, 62) & $(\mathrm{Del} / \mathrm{del}, 137)$ \\
\hline
\end{tabular}

2 Note: EW, eviscerated weight; LMW, leg muscle weight; AFW, abdominal fat pad weight; SIL, small intestine

3 length. Letters and numbers in bracket refer to genotype and number of chickens with that genotype. ${ }^{\mathrm{a}, \mathrm{b}} P<$ $4 \quad 0.05 ;{ }^{\mathrm{A}, \mathrm{B} P}<0.01$. 